\title{
AS PRÁTICAS POPULARES DE CURA UTILIZADAS POR REZADORES NO POVOADO BREJ INHO, MUNICÍPIO DE LUIZ CORREIA - PIa
}

\author{
The Popular Healing Practical Used by Prayers in the Brej inho Village, \\ in Luiz Correia City - Piauí - Brazil \\ Las Prácticas Populares de Cura Usadas por los Rezadores \\ en el Pueblo Brejinho, Ciudad de Luiz Correia - Piaú - Brasil
}

\section{Resumo}

0 estudo analisou as práticas populares de cura utilizadas por rezadores. Objetivou-se, com o trabalho, analisar as práticas populares por rezadores procurando a associação da prática com a assistência à saúde da população. Foi uma pesquisa qualitativa do tipo descritiva. Os dados foram obtidos utilizando entrevista gravada. Foram realizadas oito entrevistas. Identificaram-se as categorias: herança cultural, clientela e forma de pagamento. Conclui-se que as comunidades buscam seu próprio meio de resolver questões sobre saúde-doença, e que a parceria dos rezadores e profissionais de saúde poderia melhorar a qualidade de vida da população intermediando saberes.

Palavras-chave: Saúde. Cura pela Fé. Educação em Saúde.

\begin{abstract}
The study analyzed the popular practices of cure used by prayers. It aimed to analyze the popular practice of prayers looking for the association of the practice with the assistance of health of the population. It was a qualitative research of the descriptive type. The data was collected by recorded interview. Eight interviews were made. The identified categories were: cultural inheritance, clientele and payment form. It was conclude that the communities seek its proper way to decide questions about health, illness and the partnership among the prayers and the professionals of health could improve the quality of life of the population intermediating the knowledge.
\end{abstract}

\section{Resumen}

El estudio analizó las prácticas populares de cura usadas por rezadores. El trabajo tubo el objetivo de analizar las prácticas populares de los rezadores buscando la asociación de la práctica con la ayuda a la salud de la población. Fue una investigación cualitativa del tipo descriptiva. Los datos fueron recogidos usando entrevista grabada. Fueron realizados ocho entrevistas. Las categorías fueron identificadas como: herencia cultural, clientela y forma de pago. Concluyese que las comunidades buscan su propio medio de resolver cuestiones sobre salud, enfermedad, y que la aparcería de los rezadores y los profesionales de salud podría mejorar la calidad de vida de la población intermediando el saber.
Keywords:

Health. Faith Healing. Education in Health.
Palabras clave:

Salud. Curación por la Fé. Educación en Salud. 


\section{INTRODUÇÃO}

A participação do Ser humano como sujeito na sociedade, na cultura, na história, faz-se na medida em que é capaz de transmitir situação-limite para verificar o que existe além delas, procurando responder os desafios que a vida Ihe apresenta, muito embora as explicações que são dadas sobre alguns fenômenos sejam explicações mágicas, fabulosas, exigindo uma análise epistemológica mais detalhada.

As transformações no processo histórico, social, econômico e cultural mudaram significativamente nos últimos séculos e foram acompanhadas de mudanças no paradigma norteador da área da saúde uma vez que o modelo biomédico se mostrou insuficiente para responder a todas as questões do cuidado à saúde ${ }^{1}$

No Brasil, a mistura de invocação religiosa e cura é um fato presente em nossa sociedade, principalmente nas regiões nordeste e norte. Isto é resultante da influência cultural proveniente da colonização diversificada e plural.

Pode-se, então, observar na práxis do povo nordestino o trabalho de rezadeiras, parteiras, raizeiros, curandeiros, todos convergindo para a cura das doenças.

0 aspecto cultural apresenta-se também com o emprego de plantas medicinais no cuidar da saúde, recomendado pela ANVISA (Agência Nacional de Vigilância Sanitária) para programas de atenção primária à saúde, podendo ser uma alternativa terapêutica atrelada ao baixo custo, fácil aquisição e que se compatibiliza com aspecto cultural dos povos.

As pessoas simples retratam uma visão ingênua, e ao mesmo tempo divina, acerca da doença e da cura. A consciência intransitiva e transitiva ingênua é caracterizada pela centralização dos interesses dos homens pelas explicações mágicas e fabulosas que se dão sobre os fenômenos e pela fragilidade da argumentação. A formação do profissional de saúde nas academias em geral não retratam essa realidade do saber.

Assim, os profissionais de saúde, na maioria das vezes, ao chegar em uma localidade, recheados de conteúdos teóricopráticos adquiridos na academia e pouco ou nenhum preparo prático comunitário, esquecem ou mesmo não valorizam a cultura local, o saber comum das pessoas. 0 seu saber é imposto e não negociado. 0 saber técnico, ao se confrontar com o saber popular, não pode dominá-lo, impor-se a ele, a relação entre estes dois saberes não poderá ser a transmissão unidirecional,vertical, autoritária, mas deverá ser uma relação de diálogo, relação horizontal, bidirecional, democrática ${ }^{2}$.

Os rezadores possuem um saber místico que envolve energias muitas vezes inexplicáveis pela ciência tradicional. Segundo Barros, de 982 crianças com diarréia no nordeste do Brasil, 28\% buscam o trabalho de rezadeiras para solucionar seu problema de saúde. Isso mostra o quanto estas práticas de saúde são valorizadas pela comunidade ${ }^{3}$.

Existe nos dias atuais um maior acesso da população aos meios e serviços de saúde e farmácias. Com toda essa disponibilidade, este percentual apresentado representa o relevante papel dos rezadores para a população. Este tratar, cuidar, é permeado de uma magia pela simplicidade com que são selecionados os remédios, disponibilizados em torno de seu próprio mundo.
É preciso delimitar com clareza, a partir de quando as mulheres passam a assumir este papel de cuidadora. Na era do pensamento místico, a mulher não era cuidadora. Relata-se que quando as mulheres passaram a assumir este papel, elas foram consideradas bruxas e feiticeiras pela Igreja Católica e aconteceu a Santa Inquisição, em que milhares de mulheres foram queimadas vivas na fogueira ${ }^{4}$.

Diante de tal realidade pode-se inferir a importância dos rezadores como elo de ligação significativo entre a população e o sistema formal de saúde, demonstrando que a existência destas práticas não é exclusiva de localidades distantes, isoladas e de falta de atendimento formal de saúde, mas um fenômeno cultural que sempre existiu e que dificilmente desaparecerá, pois fazer desaparecer essas práticas é excluir a cultura de um povo.

Assim, investigou-se a realidade existente entre os rezadores e a assistência formal no povoado Brejinho, município de Luíz Correia. A este fato atrelaram-se as seguintes questões norteadoras: Como acontecem as práticas populares de cura que são utilizadas por rezadores do povoado Brejinho, município de Luiz Correia? De onde provém esse saber que tem tanta credibilidade nos meios populares?

Para responder essas questões elaborou-se o seguinte objetivo: Analisar as práticas populares de cura utilizadas por rezadores no povoado Brejinho, município de Luiz Correia - Piauí.

\section{CAMINHOS TEÓRICOS METODOLÓGICOS}

A pesquisa foi do tipo descritiva de natureza qualitativa. Optou-se pela pesquisa qualitativa por se adequar melhor à produção e análise dos dados ${ }^{5}$. 0 trabalho foi realizado no povoado Brejinho, município de Luiz Correia - PI. A produção dos dados da pesquisa aconteceu no período de dezembro de 2001 a junho de 2002.

0 município de Luiz Correia possui uma área urbana localizada na maioria das praias do município e cerca de apenas $30 \%$ da sua população de aproximadamente 23.000 (vinte e três mil) habitantes. A zona rural concentra cerca de $70 \%$ da população e fica distante do centro urbano. Todo o município hoje possui cobertura do PSF (Programa de Saúde da Família), e já existem quatro equipes de PSF. Há um grande esforço por parte das três equipes do PSF da zona rural existentes para manter uma boa cobertura de atendimento a zona rural.

Os problemas de saúde mais encontrados pela equipe são as parasitoses intestinais e as infecções respiratórias e de pele. Além disso, há relativa escassez de água. Relativa, pois embora parte do problema da falta de água tenha sido resolvido com a construção de chafarizes, há várias localidades onde 0 teor de salinidade da água é muito elevado, levando à necessidade de dessalinizador nos chafarizes, conseqüentemente dificultando a construção e principalmente a manutenção dos mesmos.

A presença do rezador nas microlocalidades da área de abrangência do estudo é grande. Percebeu-se isso pelos relatos da própria comunidade durante 0 atendimento médico e de enfermagem que muitas vezes referia ter procurado o rezador antes da consulta, ou fazia uso de "remédios" indicados pelo 
mesmo.0 local de coleta dos dados desse estudo foi o posto de atendimento do PSF dessa localidade e, por vezes, a própria casa do rezador, quando necessário.

Os sujeitos da pesquisa foram oito rezadores que residem nas microlocalidades da região do Brejinho, onde se estabeleceu como critérios para escolha desses sujeitos: 0 tempo da sua prática (pelo menos três anos); ser residente na região do PSF já citado; e concordar em participar do estudo. Anteriormente às entrevistas, foi realizada uma dinâmica de grupo com os sujeitos da pesquisa de forma sensibilizadora, tornando acolhedor o momento da entrevista.

Como pesquisa qualitativa utilizou-se, como instrumento de produção de dados, um roteiro de entrevista em associação à observação do participante, onde o entrevistador tem a possibilidade de discorrer sobre o tema proposto sem respostas ou condições pré-fixadas pelo pesquisador. A técnica de entrevista gravada em fita-cassete, ocorrida durante a visita domiciliar previamente agendada, respeitou a individualidade do sujeito participante, mantendo-se o sigilo dos dados fornecidos.

A análise dos dados baseou-se nos objetivos previamente determinados. Estabeleceu-se o corpus de comunicação estruturado a partir dos aspectos percebidos nos discursos analisados, por similaridade.

Constituíram-se então eixos geradores de discussão que correspondem aos objetivos que se buscaram atingir. Tais eixos, ao serem percebidos e captados nos discursos, deram origem a categorias. As categorias foram filtradas e sofreram nova análise para que se permitissem agrupar aquelas que fossem relevantes a todos os discursos, tornando a descrição dos temas geradores o mais abrangente possível. A síntese a seguir esquematiza a análise baseada nos eixos e categorias. A pesquisa encontra-se cadastrada no site de pesquisa com seres humanos e seguiu todas as normas previstas.

\section{ANÁLISE DOS DADOS}

As transcrições das entrevistas revelaram três categorias: herança cultural, clientela e forma de pagamento. A primeira categoria foi identificada nos discursos dos Quadros 1 e 4; as demais, nos Quadros 2 e 3, respectivamente, em anexo.

Percebeu-se uma forte influência cultural herdada dos seus antepassados. Alguns se apropriaram do saber como que de uma herança de um ente querido, outros receberam como missão essa arte de curar, passada por um familiar ou pessoa próxima.

As práticas populares de cura seguem se desenvolvendo a partir desta Herança Cultural, desta transmissão de saberes, crenças, valores e atitudes, tendo sua continuidade garantida, principalmente, pela comunidade, que as valoriza. A escolha do material a ser utilizado durante 0 ritual fica a critério de cada rezador, dependendo do tipo de cliente, do problema apresentado pelo doente e do costume de cada rezador. Além da reza como instrumento de trabalho, os rezadores utilizam também ramos de planta, e o rosário, uma espécie de terço, semelhante ao terço católico. Dentre os ramos mais utilizados foram citados a vassourinha e o pião roxo.
A importância da antropologia para a compreensão do fenômeno saúde-doença é incontestável. Junto com os dados quantitativos e com o conhecimento técnicocientífico das doenças, qualquer ação de prevenção, tratamento ou planejamento de saúde necessita levar em conta valores, atitudes e crenças de uma população ${ }^{6}$

$\mathrm{Na}$ análise dos discursos, a categoria Clientela revelou que o rezador é mais procurado para tratar de crianças. Tal fato também foi constatado porque cita o uso do benzimento como prática comumente utilizada na cura das doenças infantis, principalmente entre crianças de 0 a 2 anos. Todos referem ter freqüência esporádica da clientela, que busca 0 atendimento para o tratamento do quebrante. Tal doença se caracteriza por mal-estar, fraqueza e sonolência, por vezes acompanhados de febre, náusea e vômitos.

0 Quadro 3 apresenta o pensamento dos rezadores ante a terceira categoria - Forma de pagamento.

Como se percebe no quadro que mostra a categoria forma de pagamento, nenhum dos rezadores cobra pelo serviço realizado e todos realizam-no espontaneamente. Observouse, ainda, muita boa vontade quando da realização do trabalho e grande preocupação com a melhora ou não do cliente, formando-se até uma pequena rede de referência - contrareferência informal, onde vários deles relataram a preocupação de saber do quadro daquele cliente mesmo quando encaminhado a outro rezador, ou até mesmo ao sistema de saúde formal. Isso é claro quando o cliente já não sai daquele atendimento praticamente curado, pois todos referem grande eficácia do tratamento praticado por eles.

Os rituais costumam ser simples, sem grande preparo, onde o ramo e o rosário são utilizados para passar na pessoa em movimentos ritmados quase sempre em forma de cruz. Alguns utilizam um rosário de grande dimensão para passar a criança através dele. A reza se dá quase sempre em voz baixa, algo sussurrado, resmungado, sem uma definição precisa. Algumas são variações de orações católicas, onde estão contidas invocações a santos diversos, sendo sempre um santo de devoção do rezador.

Os ramos utilizados normalmente murcham após a reza. Indagados sobre o fato de o ramo murchar naturalmente depois de retirado da planta, eles respondem que o ramo murcha mais rápido após o ritual da reza, e que o ramo só murcha mais rápido se o problema da pessoa for realmente o quebrante. Poucas foram as rezas descritas, alguns se recusaram a dizer suas rezas, alegando que poderia ser feito mau uso delas ou com o simples argumento de não poderem revelar, sem dar maiores explicações. Outros dizem que, se a oração for ensinada, ela não serve mais para aquele rezador utilizar.

\section{CONCLUSÃO}

Por meio desta pesquisa concluiu-se que, na realidade de trabalho, mesmo com o amplo acesso ao sistema de saúde formal, as comunidades continuam buscando seu próprio meio de resolver suas questões sobre o processo de saúde-doença. 
As práticas populares têm-se mantido nas diversas culturas e sempre foram utilizadas, essencialmente no seio familiar, como primeiro recurso para minimizar ou prevenir os males. Nesta perspectiva, compreende-se prática popular como todos os recursos utilizados pelas famílias, pessoas leigas e por terapeutas populares, onde a apreensão do saber se constrói no cotidiano e se transmite de geração a geração e cujo fazer não está ligado a serviços formais de saúde.

\section{Referências}

1. Schaurich D, Padoin SMM, Paula CC, Motta MGC. Utilização da teoria humanística de Paterson e Zderad como possibilidade de prática em enfermagem pediátrica. Esc Anna Nery Rev Enferm 2005 9(2): 265-70

2. Freire P. Concientización. Buenos Aires (AR): Busqueda; 1974

3. Barros FC, Victora CG. Avaliação do manejo da diarréia em menores de cinco anos no nordeste do Brasil. J Pediatr 1989 nov/ dez; 65(11/12): 420-64

4. Medeiros LCM, Cabral IE. As plantas medicinais e a enfermagem. A arte de assistir, de curar e de transformar os saberes [tese de doutorado]. Rio de Janeiro (RJ): Escola de Enfermagem Anna Nery/UFRJ; 2001.

5. Minayo MCS, Alves PC. Saúde e doença: um olhar antropológico. Rio de janeiro(RJ): FIOCRUZ; 1994.

6. Minayo MCS. 0 desafio do conhecimento: pesquisa qualitativa em saúde. $7^{\text {a }}$ ed. São Paulo (SP): Hucitec; 2000.
Estes terapeutas, os rezadores, possuem grande credibilidade da comunidade, sendo, por vezes, os primeiros a terem contato com as pessoas doentes de uma determinada localidade. Tal proximidade da comunidade, o fácil acesso a eles, bem como o fato de não cobrarem pelo tratamento e também por estímulos culturais amplamente presentes faz com que a prática de cura dos rezadores permaneça presente em nossa realidade e se perpetue.

\section{Sobre as Autoras}

\section{Lis Cardoso Marinho Medeiros}

Enfermeira, Cirurgiã-dentista, Professora Associada I lotada no Dept ${ }^{0}$ de Biofísica e Fisiologia da Universidade Federal do Piauí, Membro do Núcleo de Estudos em Saúde Pública.

\section{Gláucia Antonia Viana de Azevedo}

Enfermeira, Prof ${ }^{a}$ Adjunta IV do Dept ${ }^{\circ}$ de Enfermagem, Coordenadora da Especialização em Saúde Pública e Membro do Núcleo de Estudos em Saúde Pública

\section{Fábio Mota Machado}

Enfermeiro do Programa Saúde da Familia do Município de Luís Correia/PI

\section{Simone Ramos de Sousa}

Enfermeira do Programa Saúde da Familia do Municíio de Luís Correia/PI

\section{Notas}

a Texto derivado de tese de doutorado defendida em 2001 (ver referência 4).

\section{ANEXOS}

QUADRO 1:

A origem do saber do rezador da localidade Brejinho, Luiz Correia -PI. 2002.

\begin{tabular}{|c|c|c|c|}
\hline Eixo gerador & Categoria & Depoentes & Discurso \\
\hline \multirow{6}{*}{ ORIGEM } & \multirow{6}{*}{$\begin{array}{l}\text { HERANÇA } \\
\text { CULTURAL }\end{array}$} & Entrevistado 1 & $\begin{array}{l}\text { R- Com meu pai. Porque meu pai fazia. Um belo dia ele disse: } \\
\text { — Você sabe que eu não vou rezar mais não. Isso não vale nada. } \\
\text { — Pois me ensine } \\
\text { — Não meu filho, não vale nada não. São só três palavras. } \\
\text { — Mas eu quero essas três palavras. } \\
\text { Ele me ensinou e eu fiquei rezando nos culumizim. }\end{array}$ \\
\hline & & Entrevistado 2 & R- Com meus avós, que já até morreram. Morreram de velhice. \\
\hline & & Entrevistado 3 & R- Com a minha mãe. Que era Católica Apostólica Romana. \\
\hline & & Entrevistado 4 & R- Com uma tia minha que já morreu. \\
\hline & & Entrevistado 6 & R- Com minha mãe. \\
\hline & & Entrevistado 8 & R - Com a minha avó. \\
\hline
\end{tabular}


QUADRO 2:

Caracterização das práticas populares de cura do rezador da localidade Brejinho, Luiz Correia - PI. 2002.

\begin{tabular}{|c|c|c|c|}
\hline Eixo gerador & Categoria & Depoentes & Discurso \\
\hline \multirow{8}{*}{ A PRÁTICA } & \multirow{8}{*}{ CLIENTELA } & Entrevistado 1 & $\mathrm{R}$ - Criança. \\
\hline & & Entrevistado 2 & $\begin{array}{l}\text { R- É mais menino. A mãe traz pra rezar e eu rezo. É dor de dente, } \\
\text { dor de cabeça e essas coisas assim. }\end{array}$ \\
\hline & & Entrevistado 3 & $\mathrm{R}$ - Eu gosto mais de criança. \\
\hline & & Entrevistado 4 & $\mathrm{R}$ - Criança. \\
\hline & & Entrevistado 5 & R- É mais criança. Mas agora mesmo eu rezei em adulto. \\
\hline & & Entrevistado 6 & $\mathrm{R}$ - Criança. \\
\hline & & Entrevistado 7 & $\begin{array}{l}\mathrm{R} \text { - É mais criança. E gente adulto, mas não é direto não. É mais } \\
\text { criança mesmo, que os pais trazem pra mim rezar. }\end{array}$ \\
\hline & & Entrevistado 8 & $\mathrm{R}$ - Criança e adultos. \\
\hline
\end{tabular}

QUADRO 3:

Caracterização das práticas populares de cura do rezador da localidade Brejinho, Luiz Correia - PI. 2002.

\begin{tabular}{|c|c|l|}
\hline Eixo gerador & Categoria & \multicolumn{1}{c|}{ Discurso } \\
\hline APRÁTICA & FORMADE & $\begin{array}{l}\text { R- Não. É um favor que eu estou fazendo. } \\
\text { R- Não Senhor. Quem quiser dar alguma coisa... É um favor né... É um favor que a gente está } \\
\text { fazendo... Né... Eu só faço favor. Às vezes me dão alguma coisa, mas eu não peço não. } \\
\text { PAGAMENTO } \\
\text { R- Eu atendo as pessoas que tem dinheiro... Se me dão alguma coisa é porque querem. Mas } \\
\text { a criança carente eu rezo por nadinha. Não quero coisa nenhuma. } \\
\text { R- Nunca cobrei. Sempre as pessoas me perguntam quanto é, e eu digo que não é nada. As } \\
\text { pessoas que tem consciência me dão uma toalha de banho, me dão um jarrozinho, me dão } \\
\text { um terço, me dão qualquer coisa. Mas cobrar mesmo eu nunca cobrei não. } \\
\text { R- Não cobro não. Eu tive de cobrar duma pessoa. Ele perguntou quanto era aí eu fui e falei } \\
\text { pra ele. Você me dá aí um agrado pra eu comprar um quilo de carne. Aí ele deu. } \\
\text { R- Não cobro nada não. A pessoa dá o que quiser. Eu não cobro não. } \\
\text { R- Não costumo cobrar } \\
\text { R- Faço por paixão, não cobro }\end{array}$ \\
\hline
\end{tabular}




\section{QUADRO 4:}

Procedimento do ritual de cura utilizado pelo rezador e a cura das doenças. Brejinho, Luiz Correia - PI. 2002.

\begin{tabular}{|c|c|c|c|}
\hline Eixo gerador & Categoria & Depoentes & Discurso \\
\hline \multirow{10}{*}{$\begin{array}{l}\text { RITUAL } \\
\text { ECURA }\end{array}$} & \multirow{10}{*}{ MATERIAL } & Entrevistado 1 & $\begin{array}{l}\text { R- Eu tenho minha devoção mesmo só e pronto. Só rezo. } \\
\text { R- Tanto faz como tanto fez. Pode ser com ramo ou não... }\end{array}$ \\
\hline & & Entrevistado 2 & $\begin{array}{l}\text { R- Eu uso só reza. } \\
\text { R-Peão roxo, mandiroba, vassourinha. }\end{array}$ \\
\hline & & Entrevistado 3 & $\begin{array}{l}\text { R- Eu utilizo a medalha, um símbolo católico que é a bíblia católica, } \\
\text { com o cinco Salomão de oito pernas ... A estrela de David com as três } \\
\text { pessoas da Santíssima Trindade da Igreja Católica. } \\
\text { R - É o credo em cruz. }\end{array}$ \\
\hline & & Entrevistado 4 & $\mathrm{R}$ - A folha do peão roxo. \\
\hline & & Entrevistado 5 & $R-A$ vassourinha. \\
\hline & & Entrevistado 6 & $\mathrm{R}$ - Uns ramos... Vassourinha. \\
\hline & & Entrevistado 7 & $\mathrm{R}$ - Em crianças, é o rosário, em gente adulto é a folha de peão roxo. \\
\hline & & Entrevistado 8 & $\begin{array}{l}\mathrm{R} \text { - Em criança a gente sempre reza com a vassourinha e folha de } \\
\text { peão, ou de carambola, em gente adulto, com o rosário. }\end{array}$ \\
\hline & & Entrevistado 7 & $\begin{array}{l}\text { R - Não, é o que eu digo para pessoa quando vem. Minha filha, se } \\
\text { você tiver fé, é a sua fé que vai lhe curar, que Deus quer que a pessoa } \\
\text { tenha fé, não é? Que quando Ele andava no mundo, aquelas pessoas } \\
\text { que tinham fé, então a pessoa era curada, bastava ver Ele. E do } \\
\text { mesmo jeito eu digo para os meus irmãos aqui. É a sua fé que vai lhe } \\
\text { curar. Aí a pessoa: Ave Maria Dona fulana, eu tenho muita fé, aí manda } \\
\text { eu rezar, aí no outro dia ela já vem bem melhor, nem parece aquela } \\
\text { que veio do jeito que veio. Já vem boazinha. Diz assim, olhe dona } \\
\text { fulana, você não viu como eu saí daqui, que eu não podia nem me } \\
\text { sentar, cheguei lá em casa me sentei, comi, dormi, e não senti mais } \\
\text { nada. Já estou aqui de volta, morta de contente. } \\
R \text { - Eu me sinto muito feliz, me sinto alegre e ainda peço que Deus } \\
\text { cuide daquela criança. Oh Jesus, ele veio do jeito que veio. Só você } \\
\text { pode curar meu Pai. Cuide dessa criança. Ah, eu fico tão preocupada } \\
\text { quando eu vejo o estado da criança, e quando é no outro dia a mãe } \\
\text { vem morta de alegre, e o pai, dona fulana, dormiu a noite todinha, } \\
\text { não vomitou mais e nem chorou mais e está aqui ele. }\end{array}$ \\
\hline & & Entrevistado 8 & $\begin{array}{l}\text { R - Se eles virem que não dão jeito, aí eles encaminham...Procure } \\
\text { outro...Outra religião... Outro meio de se curar...Que a pessoa pode } \\
\text { muito bem entender que já não é ali, tem que procurar outro... } \\
\text { (alguém cita um psiquiatra local) } \\
\text { Pelo menos o doutor fulano nas consultas dele, quando ele vê que } \\
\text { não dá certo ele diz logo o que é e o que não é, e manda a pessoa } \\
\text { procurar um rezador, outra pessoa que faça ele ficar bom. E aí a } \\
\text { pessoa se manifesta para outro lado.Porque se ele conseguisse ficar } \\
\text { bom a troco de remédios, só os remédios que ele tomasse já ficaria } \\
\text { bom. Agora não é problema de remédio, tem que ser por oração, } \\
\text { tem que ser por outros meios de reza para que aquela pessoa se } \\
\text { restabeleça e tenha saúde. }\end{array}$ \\
\hline
\end{tabular}

